\title{
SOUND ABSORPTION PROPERTY OF NONWOVEN BASED COMPOSITES
}

\author{
Eulalia Gliścińska, Marina Michalak, Izabella Krucińska
}

Lodz University of Technology, Department of Material and Commodity Sciences and Textile Metrology, 90-924 Łódź, ul. Żeromskiego 116, Poland

e-mail: klata@p.lodz.pl

\begin{abstract}
:
Sound absorbing materials used to provide optimal conditions in rooms can be applied in the form of textiles with a special structure such as nonwovens or fibre-containing composites. Nonwovens can be successfully used to make thermoplastic composites by thermal pressing. This paper presents the comparison of the sound absorbing properties of needled nonwovens and composites made from them. Composites with various densities can be made of nonwovens with various percentage contents of filling and matrix fibres. The sound absorption by composites with similar thickness, about several millimetres, is slightly lower than that by the laminar nonwoven packs used for their making. The optimal content of the filling fibres in the composite, when its sound absorption coefficient reaches the highest values, is at the level of $10 \mathrm{wt} \%$. With the increase in the content of filling fibres the composite density decreases. In the case of the composite with $10 \mathrm{wt}$ \% of filling fibres, its density is the highest among the composites investigated, and the increase in absorption of high-frequency sounds is the highest. Imparting a relief with a protrusion diameter over $10 \mathrm{~mm}$ to the composite surface, we can increase the sound absorption of that composite.
\end{abstract}

\section{Keywords:}

Fibre, composite, sound absorption, needled nonwoven, thermoplastic matrix

\section{Introduction}

The wide range of composites available is closely connected with the variety of components that can be combined with each other, and also the diversity of the structures obtained [1,2] The type of composite components influences the selection of a proper processing technique and the composite properties obtained. From among various forms of the filling component, the fibres are the most beneficial from the point of view of the composite mechanical properties.

The composite properties, besides the technological parameters of the manufacturing process and the parameters of filling fibres such as length, thickness, type of spinning finish and strength, are also affected by the type of matrix material, percentage composition of particular components, degree of their blending and the form of the fibres used. In the case of composites with a thermoplastic matrix, the filling fibres can consist either of staple or continuous filaments as well as in the form of a linear or flat fabric. The direction of fibre arrangement, flat fabric structure and the arrangement of layers to be combined can also be different. It is beneficial to use a hybrid fabric consisting of both filling fibres and fibres constituting the composite matrix. Such a type of fabric can provide a high degree of component blending in the composite.

In the case of a linear textile fabric, the highest degree of component blending is assured by hybrid yarns composed of reinforcing fibres and fibres of the matrix material, e.g. twisted or looped yarn, Kemafil, Schappe and textured yarns [3,4].
In the case of a flat fabric, a high blending degree is obtained by nonwoven techniques. An opportunity to process the widest range of fibres is created by the needling technique where the web as intermediate product is made by the carding system. This system makes it possible to arrange fibres in a longitudinal, crosswise or cruciform way in relation to the fabric axis. Chemical fibres can be blended with natural fibres, which are often used to make thermoplastic composites on account of the prospect of their complete utilisation.

Nonwovens owing to their great surface area, especially those made on the basis of natural fibres or active carbon fibres, are often mentioned beside spacer knitted fabrics as fibrous materials with a relatively good acoustic behaviour [5-12] with respect to conventional materials such as foams.

There are known acoustic fibrous webs consisting of several layers of web made by the carding system, divided by nanofibre layers [13]. However, such materials are not a sufficiently good solution under all application conditions. Sometimes a sound absorbent in the form of a composite meeting specified requirements resulting from exploitation conditions is required to be used. Composites, depending on their structure, can fulfil various expectations connected with their strength, rigidity, resistance, weight, thickness or surface quality. However, there are still only few research results available concerning composite materials with sound absorbing properties [10].

Generally, sound absorbing materials are characterised by a porous structure and the coefficients of sound absorption are proportional to their thickness and inversely proportional to the 
resistance of air flowing through them. The density of material exerts, however, a greater influence on sound absorption than the fabric thickness or weight [10]. In the case of composites, the values of sound absorption coefficients are small for low frequencies and usually they increase with increasing frequency. Nowadays, more and more one tends to obtain new sound absorbing materials with appropriately good properties of sound absorption, high stability and resistance to various factors, and with proper form and surface quality, as well as the price being attractive $[2,14,15]$. A promising solution, in respect of both economy and acoustic properties of the material obtained, would be the use of waste fibres, especially environmentally friendly ones [15-19].

In this study, we created thermoplastic composites based on the environmentally friendly components, each of which was used in a fibrous form. The packages subjected to pressing consisted of needled nonwoven layers with various percentage contents of filling fibres and matrix fibres. Two types of composites with a smooth surface and with a relief-imparted surface were made. The aim of the study was to compare the sound absorbing properties of the nonwovens and the composites made of them as well as to determine the dependence of the composite sound absorbing properties on the percentage content of filling fibres. The point was also to impart a texture to the composite surface that could increase its sound absorption.

\section{Experimental}

\subsection{Materials}

As a material of composite matrix, polylactide (PLA) fibres $6.7 \mathrm{dtex} / 64 \mathrm{~mm}$ characterised by melting point in the range of $165-170^{\circ} \mathrm{C}$ were used. PLA fibres, under the name of Ingeo Fibre type SLN2660D, with a finishing composition containing PLA resin and no hazardous compounds, were provided by the Far Eastern Textile Ltd. (Taiwan). These fibres made of aliphatic polyester are completely biodegradable and pose no significant hazard to the environment.

Standard manmade Viscose fibres 4.4 dtex/70 mm, characterised by the destruction point at $174-190^{\circ} \mathrm{C}$, were used as the composite filling.

\subsection{Manufacturing of nonwovens}

The thermoplastic model composites were obtained from the nonwoven multilayer structures.

The latter were made of needled nonwovens obtained from PLA and viscose fibres with various percentage contents. For comparison purposes, a PLA nonwoven was made. Depending on the mass per square metre of the given nonwoven, the number of its layers in the package was appropriately selected.

Needle punched nonwovens were manufactured from the fleece with cross system of fibre's arrangement, which was obtained on the roller card. Needle punching of fleece layer was carried out on the needle punching machine Asselin (France) at the following technological parameters: kind of needles $-15 \times 18 \times 40$ $x 3 \frac{1}{2} \mathrm{RB}$; number of needle punching $-40 / \mathrm{cm}^{2}$; depth of needle punching $-12 \mathrm{~mm}$. Five variants of blended nonwovens were made with various percentage contents of constituent fibres: $1.90 \%$ of PLA fibres and $10 \%$ of viscose fibres - symbol " $90 / 10$ " 2. $80 \%$ of PLA fibres and $20 \%$ of viscose fibres - symbol " $80 / 20$ " 3. $70 \%$ of PLA fibres and $30 \%$ of viscose fibres - symbol " $70 / 30$ " 4. $60 \%$ of PLA fibres and $40 \%$ of viscose fibres - symbol " $60 / 40$ " $5.50 \%$ of PLA fibres and $50 \%$ of viscose fibres - symbol " $50 / 50$ " and for comparison purposes: $100 \%$ PLA nonwoven.

\subsection{Manufacturing of composites}

\section{With a smooth surface}

The composites were manufactured on a hydraulic press machine with a water-cooling system (Hydromega, Poland). The upper and lower mold plates were smooth. The multilayer nonwoven's structure was wrapped by Teflon foil to prevent the molten polymer propagation during the pressing process under the following conditions:

\section{Heating up to $170^{\circ} \mathrm{C}$, upper plate not maximally pressed down, \\ 2. Consolidation during $5 \mathrm{~min}$ at $0.27 \mathrm{MPa}$, \\ 3. Cooling to $25^{\circ} \mathrm{C}$ at $0.27 \mathrm{MPa}$.}

\section{With a relief-imparted surface}

In addition to the composites with smooth surfaces, composites with a relief-shaped surface were made of the selected nonwoven. These composites were investigated in order to increase the sound absorption in an easy and inexpensive way. To obtain a composite with a diversified surface structure, a Teflon plate with orifices was used to produce flattened protrusions on the given composite surface. Depending on the orifice diameter of the plate used ( $\phi=5,10,13$ and $17 \mathrm{~mm}$ ), the protrusion size was different. During the pressing process with the plate, the pressure used was $0.25 \mathrm{MPa}$. The composite thickness with flattened protrusions was diversified on its surface area: on the protrusion spots it was greater amounting to $5.9 \mathrm{~mm}$ at the average, while between the protrusions it was smaller amounting to $4.3 \mathrm{~mm}$.

\subsection{Methods}

The mass per square metre of nonwovens was established according to the standard PN-EN 29073-1 (ISO 9073-1) and the thickness of composites according to the standard ISO 9073-2. The density of composites was calculated from the mass per square metre and thickness. The acoustic properties of composites were measured by means of a small-sized impedance tube type 4206 (Brüel\&Kjaer, Denmark) using two quarter-inch Condenser Microphones Type 4187 (Figure 1). The physical sound absorption coefficient (a quotient of acoustic energy absorbed by the given material to the energy of acoustic incident wave) was determined for each sample by the method using the coefficient of standing wave, according to the standard procedure: PN-EN ISO 10534-1 in the frequency range of $500-6400 \mathrm{~Hz}$. The diameter of the samples investigated was equal to $29 \mathrm{~mm}$. 


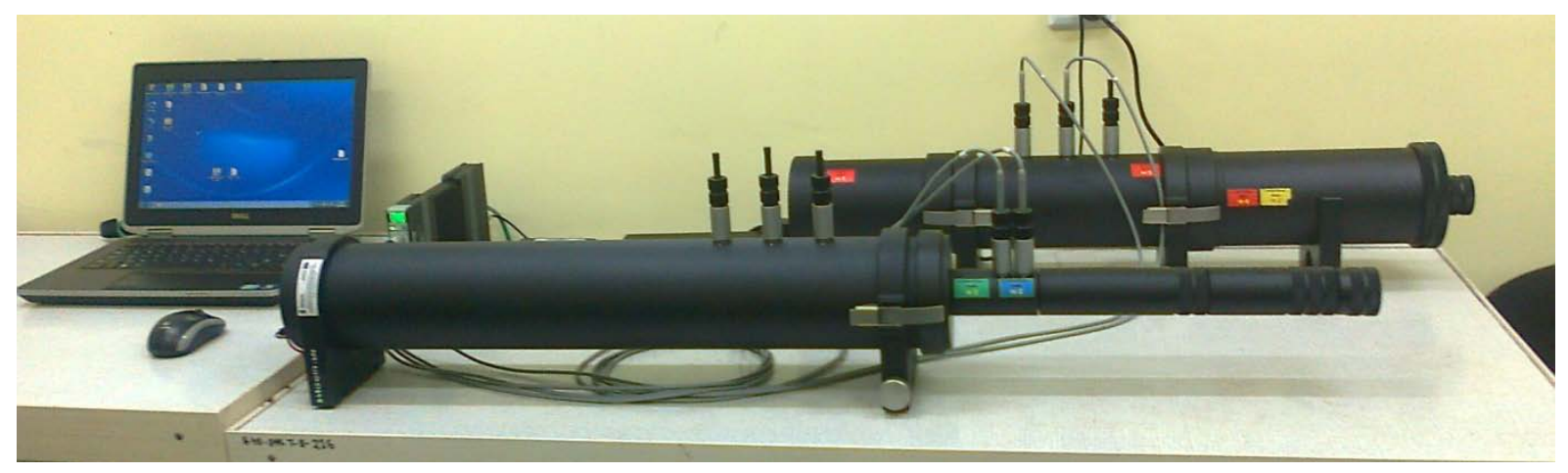

Figure 1. The set-up with Kundt tube.

\section{Results}

\subsection{Nonwovens}

In order to obtain multilayer structures with diversified percentage of components, five variants of hybrid needle punched nonwovens from PLA and viscose fibres blends were manufactured. The PLA fibre content was changed from $90 \%$ to $50 \%$ and viscose fibre content from $10 \%$ to $50 \%$ to prepare nonwovens with the following PLA and viscose fibre composition: $90 / 10,80 / 20,70 / 30,60 / 40$ and 50/50, respectively (Table 1).

Table 1. Characteristics of nonwovens.

\begin{tabular}{|c|c|c|}
\hline Material symbol & $\begin{array}{c}\text { Fibre content } \\
\text { (PLA/viscose) } \\
\text { (\%/\%) }\end{array}$ & $\begin{array}{c}\text { Mass per square } \\
\text { metre } \\
\mathbf{( g / m}^{2} \mathbf{)}\end{array}$ \\
\hline $\mathbf{1 0 0 / 0}$ & $100 / 0$ & 117.69 \\
\hline $\mathbf{9 0 / 1 0}$ & $90 / 10$ & 77.16 \\
\hline $\mathbf{8 0 / 2 0}$ & $80 / 20$ & 130.90 \\
\hline $\mathbf{7 0 / 3 0}$ & $70 / 30$ & 112.70 \\
\hline $\mathbf{6 0 / 4 0}$ & $60 / 40$ & 85.98 \\
\hline $\mathbf{5 0 / 5 0}$ & $50 / 50$ & 91.45 \\
\hline
\end{tabular}

The number of layers in the multilayer structure was from 6 to 10 depending on the nonwoven surface mass.

The measurement results of the sound absorption by the packages composed of several layers of the given nonwoven are shown in Figure 2. The number of layers was the same as that in the preparation of composites. The symbols of nonwovens are given in the legend.

The absorption coefficient of nonwovens generally increases with increasing sound wave frequency for all ranges. For the following nonwovens, 100/0,80/20, 70/30 and 60/40, the absorption coefficient-frequency dependences are very similar. The maximum of the absorption coefficient of these nonwovens is about 0.9 and above at sound frequency of 6400 $\mathrm{Hz}$. The absorption coefficient-sound frequency dependence of nonwoven $50 / 50$ is similar to the above ones but the values of absorption coefficient are slightly lower and the maximum value is about 0.75 . The absorption coefficient of nonwoven $90 / 10$ increases from the beginning of sound frequency range to $4000 \mathrm{~Hz}$ and in this range it is higher than of other nonwovens. Next, from $5000 \mathrm{~Hz}$ it is weakly lowered. At $5000 \mathrm{~Hz}$, the value of absorption coefficient is 0.85 , and at the frequency of $6400 \mathrm{~Hz}$ it amounts to 0.82. Such irregular dependence of sound absorption coefficient versus frequency for regular

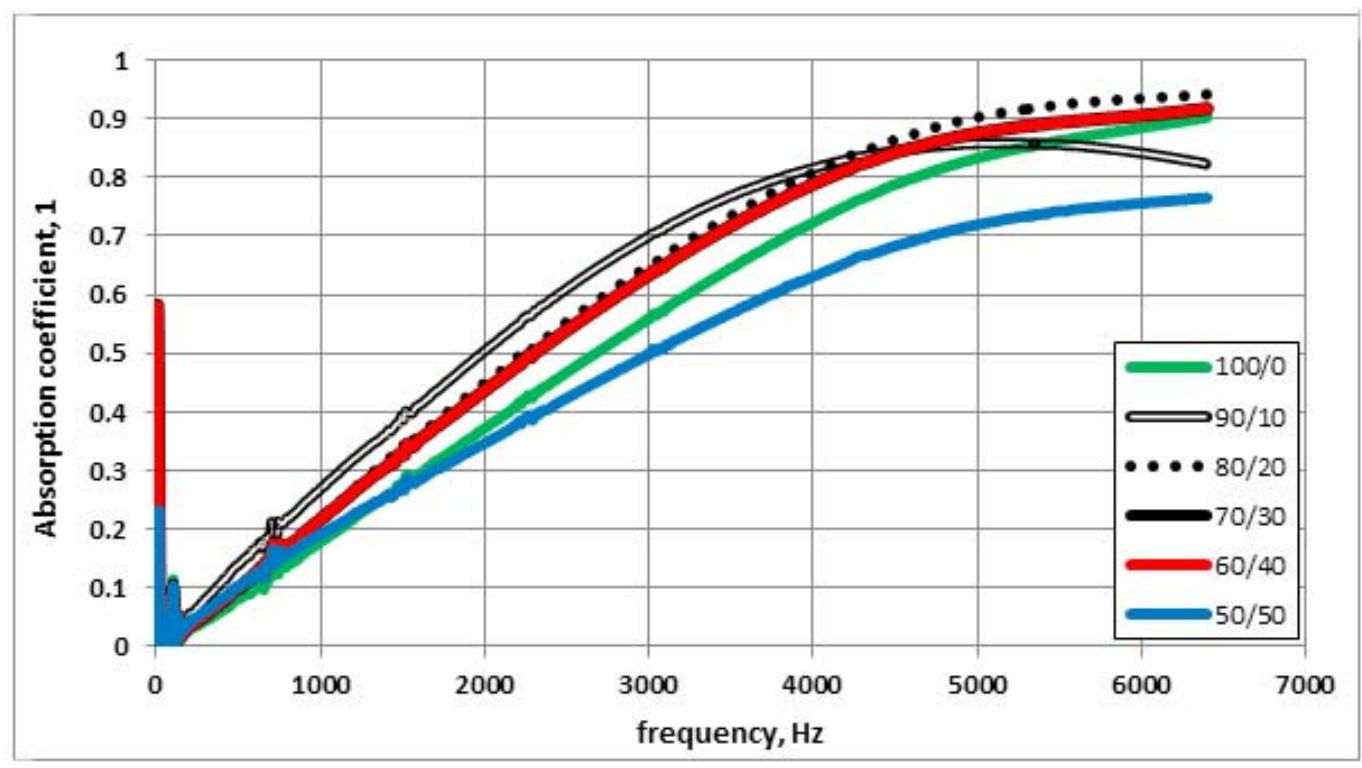

Figure 2. Absorption coefficient of nonwoven samples as a function of sound frequency. 
growing parameter of nonwovens is observed in investigations of other authors [20]. They studied the absorption coefficient for nonwovens with various thickness.

\subsection{Composites with a smooth surface}

From each kind of nonwovens, the composites with a smooth surface were manufactured. The characteristics of composites obtained between plane plates are presented in Table 2 .

Table 2. Characteristics of composite materials.

\begin{tabular}{|c|c|c|c|}
\hline $\begin{array}{c}\text { Material } \\
\text { symbol }\end{array}$ & $\begin{array}{c}\text { Fibre content } \\
\text { (PLA/viscose) } \\
\mathbf{( \% / \% )}\end{array}$ & $\begin{array}{c}\text { Thickness } \\
\mathbf{( m m )}\end{array}$ & $\begin{array}{c}\text { Density } \\
\mathbf{( k g / m}^{\mathbf{}} \mathbf{)}\end{array}$ \\
\hline $\mathbf{1 0 0 / 0}$ & $100 / 0$ & 3.83 & 1321 \\
\hline $\mathbf{9 0 / 1 0}$ & $90 / 10$ & 4.57 & 520 \\
\hline $\mathbf{8 0 / 2 0}$ & $80 / 20$ & 4.85 & 324 \\
\hline $\mathbf{7 0 / 3 0}$ & $70 / 30$ & 4.55 & 301 \\
\hline $\mathbf{6 0 / 4 0}$ & $60 / 40$ & 5.33 & 223 \\
\hline $\mathbf{5 0 / 5 0}$ & $50 / 50$ & 4.57 & 177 \\
\hline
\end{tabular}

In the case of the composites obtained with similar thicknesses, one can observe a dependence of composite density on the content of filling fibres. The composite density decreases with increasing content of filling fibres. The density of the material obtained by pressing the PLA nonwoven, containing no filling fibres, amounts to $1321 \mathrm{~kg} / \mathrm{m}^{3}$, while a $10 \%$ content of filling fibres in the composite decreases the composite density to $520 \mathrm{~kg} / \mathrm{m}^{3}$, and the filling fibres content of $50 \%$ decreases the composite density to $177 \mathrm{~kg} / \mathrm{m}^{3}$.

Figure 3 shows the sound absorption coefficient of composite materials with various fibre compositions as a function of frequencies.
The absorption coefficient of composites with filling fibres generally increases with increasing sound wave frequency for all ranges, as for nonwovens. The values of sound absorption coefficient of the composite materials are slightly lower than the corresponding values for nonwovens, because the material structure changes during the pressing process.

The material prepared from nonwoven of $100 \%$ PLA fibres is characterised by the least value of sound absorption. The character of the absorption coefficient-sound frequency dependence is different than that in the case of PLA/viscose composites. The absorption coefficient within the range of $1000-4000 \mathrm{~Hz}$ is constant at the level of 0.1 , and then it increases strongly to the value of 0.4 .

Such small values of absorption coefficient are due to the uniform structure of the PLA material similar to plastic, with less porosity (density of the $100 \%$ PLA material is more higher than density of PLA/viscose composites, and close to density of the PLA fibres: $1250 \mathrm{~kg} / \mathrm{m}^{3}$ from the literature $[18,21]$ and $1162 \mathrm{~kg} / \mathrm{m}^{3}$ measured for studied fibres).

The absorption coefficient-frequency dependences of the composites with symbols $80 / 20,70 / 30,60 / 40$ and 50/50 are very similar. With the increase in sound frequency, the absorption coefficient also increases. The maximum of absorption coefficient of the composites $80 / 20,70 / 30$ and $60 / 40$ is about 0.65 . For the composite $50 / 50$, the values of sound absorption coefficient are higher in all frequency ranges and the maximum is about 0.75 .

The character of the absorption coefficient-frequency dependence of the composite $90 / 10$ is similar to those of the composites with symbols $80 / 20,70 / 30,60 / 40$ and $50 / 50$ till the frequency of $3750 \mathrm{~Hz}$. From this value, for high-frequency sounds, the absorption coefficient is increasing more strongly than for other composites characterised by the considerably lower density, which is consistent with literature data [10]. The maximum of the absorption coefficient for this composite is 0.95 .

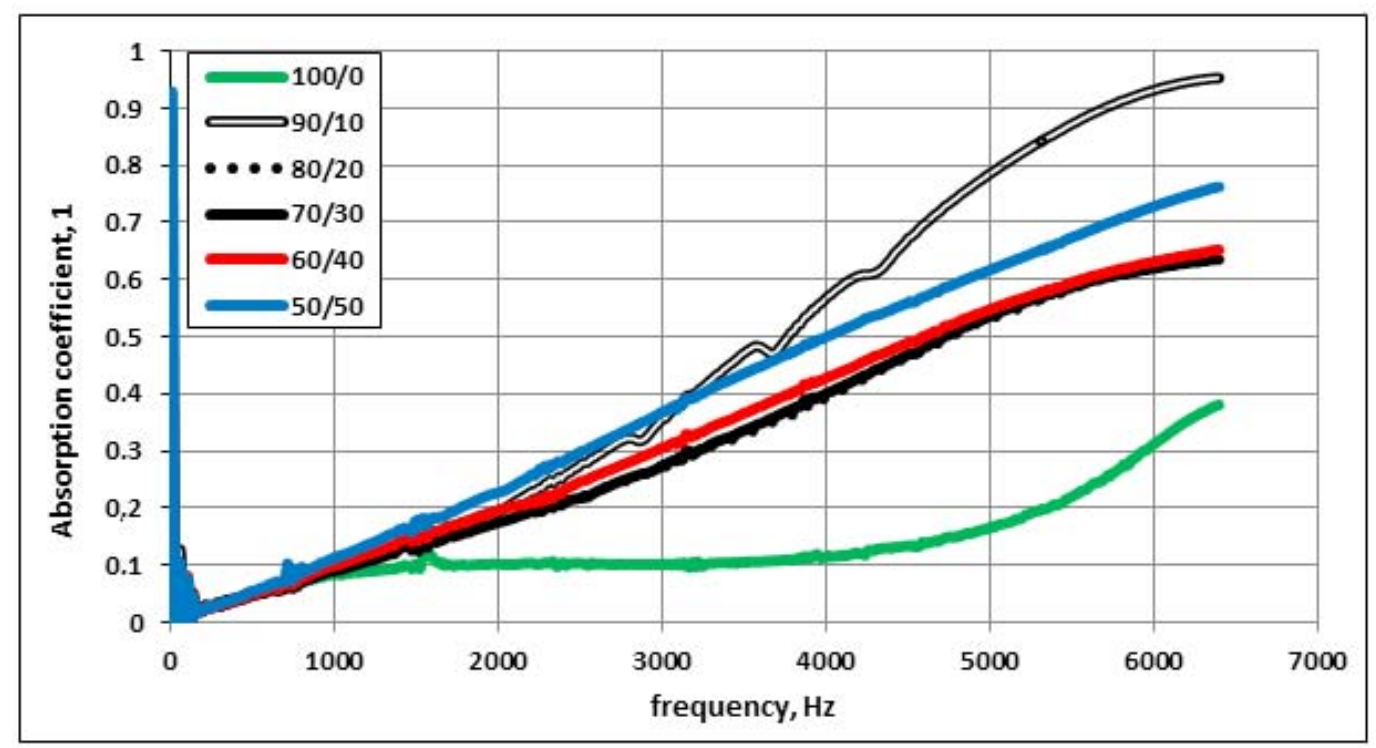

Figure 3. Absorption coefficient of composite material samples as a function of sound frequency. 
The optimal content of filling fibres in the sound absorbing composites manufactured from the PLA/viscose nonwoven is 10 wt. \%.

Composite 60/40, despite having the highest thickness and a relatively low density, did not show the highest sound absorption. In the case of composite 50/50 with the lowest density, highest softness and a relatively high thickness, the values of the sound absorption coefficient are at the highest level but only for the frequencies not exceeding $3200 \mathrm{~Hz}$. At high frequencies exceeding $3200 \mathrm{~Hz}$, the highest sound absorption is shown by composite $90 / 10$ with the highest density among studied composites. In accordance with the literature [10], fabric density has more effect than fabric thickness or weight on sound absorption. Generally, for porous materials as studied composites, low density gives high sound absorption coefficient at low frequencies, but high density gives high sound absorption coefficient at mid and high frequencies and this problem is very complicated [22,23].

\subsection{Composites with a relief-imparted surface}

Further tests were carried out to increase the sound absorption coefficient of composites by their modification. The modification consisted in imparting a relief, characterised by uniformly distributed protrusions (Figure 4), to one surface of composite 80/20.

The thickness of the composite samples between the protrusions amounted to $4.3 \mathrm{~mm}$ at the average while the thickness of samples on the protrusion spots, in their middle part, was $5.9 \mathrm{~mm}$ on an average. The results of the sound absorption coefficient of composites with protrusions as a function of sound frequency are presented in Figure 5.

The imparting of relief to the composite surface generally increases the sound absorption. The value of the sound absorption coefficient depends on the protrusion size. A protrusion with a diameter at its base amounting to $5 \mathrm{~mm}$ does not increase the coefficient of sound absorption. The protrusions with a diameter at their base exceeding $10 \mathrm{~mm}$ considerably increase the sound absorption coefficient. The optimal increase is obtained for composites containing protrusions with diameters in the range of $13-17 \mathrm{~mm}$. The sound absorption coefficient of the composites with protrusions of diameters 13 and $17 \mathrm{~mm}$ slightly decreases at high frequencies. So, further increase in the diameter of the protrusions on the composite surface is not recommended. The character of sound absorption dependence on the dimensions of protrusions situated on the composite surface probably results from the relationship between dimensions of places responsible for sound focus and sound wavelength [10]. This problem is too complicated to clearly explain on the basis of these preliminary studies and requires subsequent, separate investigations.

\section{Conclusions}

The absorption coefficient of the PLA/viscose nonwovens investigated generally increases with increasing sound wave frequency within its whole range. An exception is in the case of one variant of nonwovens, i.e. 90/10, where at high frequencies, that is, from $5000 \mathrm{~Hz}$, the sound absorption slightly decreases.

The pressing process of PLA/viscose nonwovens made it possible to obtain equally thick thermoplastic sound absorbing composites causing only a decrease in the sound absorption coefficient of the material.

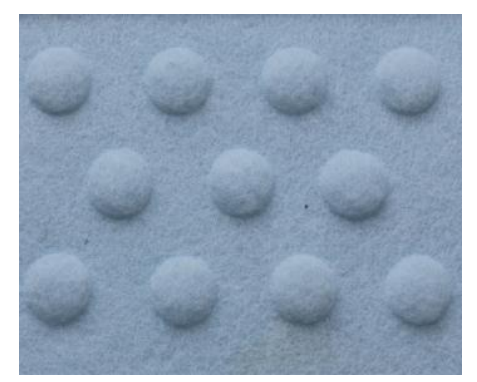

Figure 4. Composite with a relief-imparted surface.

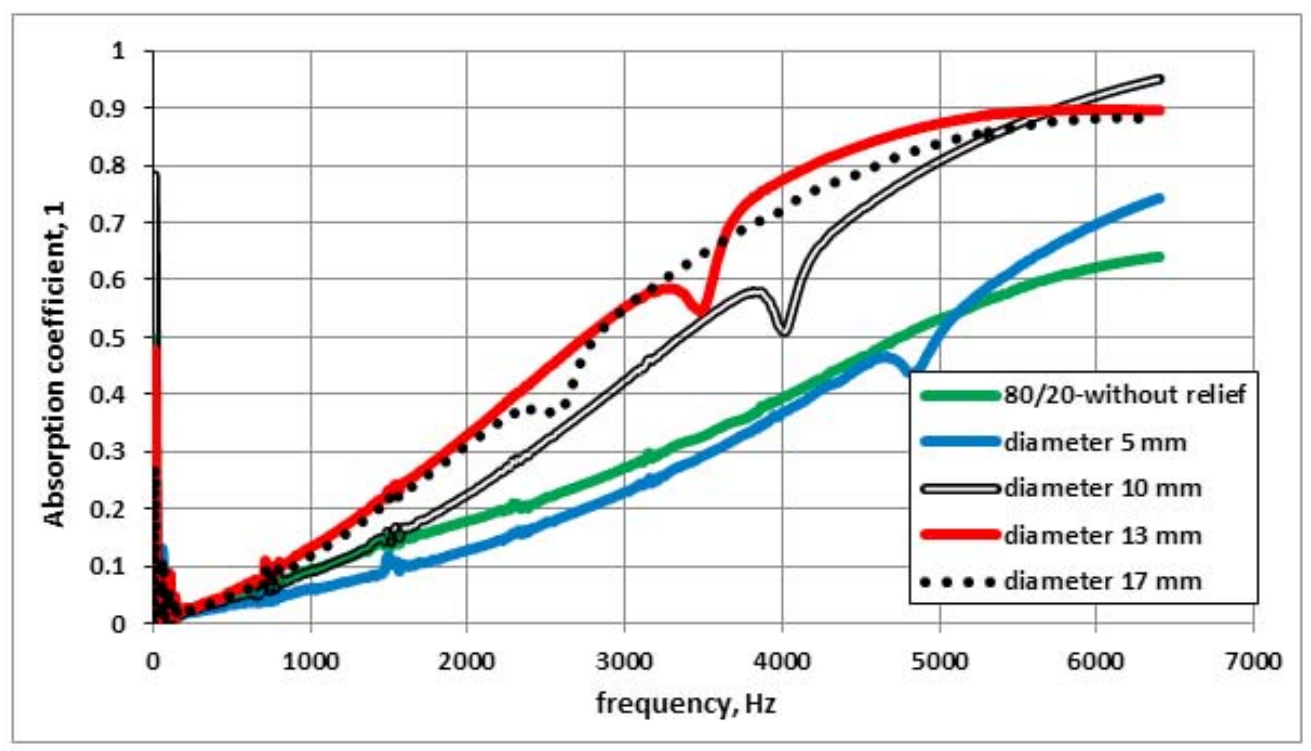

Figure 5. Absorption coefficient of composite material samples with protrusions as a function of sound frequency. 
The absorption coefficient of composites generally increases with increasing the sound wave frequency for all ranges, as for nonwovens.

The presence of filling fibres in the thermoplastic matrix positively influences the composite sound absorption. The optimal content of the filling fibres in the composite when its sound absorption coefficient reaches the highest values amounts to $10 \mathrm{wt} . \%$.

With the increase in the content of filling fibres, the composite density decreases. In the case of the composite containing 10 wt.\% of filling fibres, its density is the highest among the composites studied and the increase in absorption for high-frequency sounds is the highest. The character of the dependence of sound absorption coefficient on frequency for this composite is different from that of the dependence for a nonwoven of the same composition. In the composite, this dependence increases within the whole frequency range investigated, while in nonwovens the sound absorption coefficient decreases after reaching its maximal value.

Imparting a relief with a protrusion diameter over $10 \mathrm{~mm}$ to the composite surface, it is possible to increase the sound absorption of that composite.

\section{Acknowledgements}

This work was supported by the Project "Utilization of biomass for the preparation of environmentally friendly polymer materials" (Biomass) - POIG.01.01.02-10-123/09.

\section{References}

[1] Vinson, J.R., \& Sierakowski, R.L. (1986). The behaviour of structures composed of composite materials. Martinus Nijhoff Publishers. Dordrecht.

[2] Turkiewicz, J., \& Sikora, J. (2011). Investigations of the sound absorption coefficient of composite materials. Mechanics Technical Transactions, 16, 113-122.

[3] Lauke, B., Bunzel, U., Schneider, K. (1998). Effect of hybrid yarn structure on the delamination behaviour of thermoplastic composites. Composites: Part A, Vol. 29A, 1397-1409.

[4] Krucińska, I., Klata, E., Ankudowicz, W., Dopierała, H. (2001). Influence of the structure of hybrid yarns on the mechanical properties of thermoplastic composites. Fibres and Textiles in Eastern Europe, Vol. 9, No. 2(33), 38-41.

[5] Liu, Y., Hu, H. (2010). Sound absorption behaviour of knitted spacer fabrics. Textile Research Journal, Vol. 80, No. 18, 1949-1957.

[6] Parikh, D.V., Chen, Y., Sun, L. (2006). Reducing automotive interior noise with natural fiber nonwoven floor covering systems. Textile Research Journal, Vol. 76, No. 11, 813-820.

[7] Öztürk, M. K., Nergis, B., Candan, C. (2011). Development of a spacer knitted fabric for sound absorbent acoustic panels. International Congress of Innovative Textiles, ICONTEX2011, Istanbul, 347-353.

[8] Jiang, N., Chen, J.Y., Parikh, D.V. (2009). Acoustical evaluation of carbonized and activated cotton nonwovens. Bioresource Technology, 100, 6533-6536.

[9] Kyoichi, W., Yoshiaki, M., Kouichi, N., Hiroshi, S. (1999). Development of high-performance all-polyester soundabsorbing materials. JSAE Review, 20, 357-362.

[10] Na, Y., Lancaster, J., Casali, J. (2007). Sound absorption coefficient of micro-fiber fabrics by reverberation room method. Textile Research Journal, Vol. 77, No. 5, 330-335.

[11] Mirjalili, S. A., Mohammad-Shahi, M. (2012). Investigation on the acoustic characteristics of multi-layer nonwoven structures. Part 1 - Multi-layer nonwoven structures with the simple configuration. Fibres and Textiles in Eastern Europe, Vol. 20, 3(92), 73-77.

[12] Jia Horng, L., You Cheng, L., Chao Chiung, H., Chia Chang, L., Chin Mei, L., Ching Wen, L. (2010). Manufacturing process of sound absorption composite planks. Advanced Materials Research, Vol. 97-101, 1801-1804.

[13] Kalinova, K., Sanetrnik, F., Jirsak, O., Mares, L. (2006). Layered sound absorptive non-woven fabric. WO 2006/108363 A2.

[14] Maderuelo-Sanz, R., Nadal-Gisbert, A. V., Crespo-Amorós, J. E., Parres-García, F. (2012). A novel sound absorber with recycled fibers coming from end of life tires (ELTS). Applied Acoustics, 73, 402-408.

[15] Ersoy, S., Küçük, H. (2009). Investigation of industrial tealeaf-fibre waste material for its sound absorption properties. Applied Acoustics, 70, 215-220.

[16] Narendra, R., Yiqi, Y. (2005). Biofibers from agricultural byproducts for industrial applications. Trends in Biotechnology, Vol. 23, No. 1, 22-27.

[17] Fatima, S., Mohanty, A.R. (2011). Acoustical and fireretardant properties of jute composite materials. Applied Acoustics, 72, 108-114.

[18] Dakai, C., Jing, L., Jie, R. (2010). Study on sound absorption property of ramie fiber reinforced poly (L-lactic acid) composites: Morphology and properties. Composites: Part A, 41, 1012-1018.

[19] El Hajj, N., Mboumba-Mamboundou, B., Dheilly, R.-M., Aboura, Z. (2011). Development of thermal insulating and sound absorbing agro-sourced materials from auto linked flax-tows. Industrial Crops and Products, 34, 921-928.

[20] Süvari, F., Ulcay, Y. (2011). Experimental investigation into sound absorptive properties of PET/PP high loft nonwovens. International Congress of Innovative Textiles, ICONTEX2011, Istanbul, 368-373.

[21] Avine, O., Khoddami, A. (2009). Overview of poly(lactic acid) (PLA) fibre. Fibre Chemistry, Vol. 41, No. 6, 391-401.

[22] Koizumi, T., Tsujiuchi, N., Adachi, A. (2002). The development of sound absorbing materials using natural bamboo fibers, high performance. WIT Press, 157-166.

[23] Küçük, M., Korkmaz, Y. (2012). The effect of physical parameters on sound absorption properties of natural fiber mixed nonwoven composites. Textile Research Journal, 82(20), 2043-2053. 